posals supported by the whole weight of the B.M.A. would prove difficult to resist. These are being drawn up urgently by the Association. If an inquiry is set up they should be put to it as a reasoned case for reform. Should the call for an inquiry be rejected, then the G.M.C. should realize that the B.M.A. can no longer tell its members that there is real justification for a retention fee.

\section{Medical Treatment of Enlarged Prostate}

"Hormones may cure prostatic sufferers" was a recent newspaper headline ${ }^{1}$ that must have aroused the hopes of many of those readers with symptoms of prostatic enlargement. Unfortunately the hope lies in the future. The report referred to a trial ${ }^{2}$ of medrogestone, an oral progestogen and antiandrogen. Despite some reported improvement an analysis of the study shows that there was no objective evidence of shrinkage of the gland by the only two accepted means of assessment-namely, rates of urine flow and estimations of residual urine. ${ }^{3}$ The latter investigation, performed by an isotope method which the authors admitted gave a wide variation on repeated estimations, showed no difference between placebo and hormone; flow rates were not performed. The evidence for a decrease in prostatic size was by digital, cystoscopic, and radiological assessment-procedures that give questionable results owing to the inevitable subjective element in them.

19-nor-17-alpha hydroxy-progesterone caproate (SH 582), a powerful progestogen, has recently been assessed by controlled trials after promising initial uncontrolled results. ${ }^{3}$ In a double-blind crossover trial this hormone or a placebo was given intramuscularly once a week for 24 weeks to 21 patients by J. C. Gingell and colleagues. ${ }^{4}$ They found that SH 582 did not alter the flow rates or residual urines, though nocturnal frequency was reduced.

D. A. Aubrey and T. Khosla ${ }^{5}$ tried the same drug on patients who were either too ill for operation or whose symptoms were too mild to require it. They assessed progress by estimations of residual urine by catheter, by rectal and cystourethrographic measurement of prostatic size, and by scoring for symptoms. The trial was on 24 volunteer inpatients and outpatients at Newport, Monmouthshire. Eleven patients received a placebo for the first 12 weeks of the trial and then SH 582 for the next 12 weeks. The second group of 13 patients received the hormone for the first 12 weeks and then the placebo for the 12 weeks after that. In the first group there was a $50 \%$ improvement in symptoms after the placebo and no further improvements after SH 582. In the second group there was a $60 \%$ improvement after SH 582 and this increased to a $73 \%$ improvement on the placebo. The mean volume of residual urine in the first group was largely unaffected by placebo but was "significantly reduced" after treatment with SH 582. The mean reduction was from $76.5 \mathrm{ml}$ to 42.2 , and though this was statistically significant its clinical significance is another matter. In the second group the decrease was not statistically significant. The prostatic size assessed by radiography was reduced in both groups after the hormone but not after the placebo. Nine of the 24 patients were excluded from this assessment, however, as the cystourethrograms were unsatisfactory, and furthermore radiographic assessment is itself unreliable because many glands do not enlarge upwards into the bladder and so lack a measurable lateral dimension. A. J. S. Burger ${ }^{6}$ has suggested that SH 582 may be the future treatment of choice for prostatic enlargement, but the trials reported so far make it difficult to share his enthusiasm.

Nystatin, a polyene macrolide, has been evaluated in a controlled trial ${ }^{7}$ and was found to be no better than a placebo in obviating the need for prostatectomy in a group of 31 patients.

In any trial of the treatment of enlarged prostates we need objective assessment of decreasing urinary obstruction. A catheter estimation of the residual urine and accurate and repeated records of the urine flow are required, as these two measurements are not affected by placebo treatment. ${ }^{8}$ Even these measurements can be improved without altering the resistance to urinary flow by increasing the strength of the detrusor contraction, so that urodynamic studies should ideally be undertaken in assessing the effects of drugs.

Many factors make controlled trials difficult to construct. Enlarged prostates, for instance, come in every shape and size, and there is often no relationship between the size of the gland and the degree of urinary obstruction. Thus, only $4 \%$ of males over 80 need prostatectomy, whereas $75 \%$ of them at this age will have necropsy evidence of prostatic enlargement.9 Though the obstruction may be produced by an elongation and compression of the prostatic urethra by a bulky adenoma, it is frequently produced by a small fibrous prostate or by hypertrophy of muscular tissue at the bladder neck. These variations were illustrated clearly by $A$. Randall ${ }^{10} 40$ years ago, and in his series a median bar accounted for $18 \%$ of obstructions.

F. K. Mostofi1 and L. M. Franks ${ }^{12}$ found that a large proportion of glands removed surgically show other pathological processes in addition to the hypertrophy, such as recent or healed infarcts, acute or chronic inflammation, or unsuspected carcinoma. The hyperplastic tissue may consist of varying proportions of acinar, vascular, fibrous, or muscular tissue, and cystic changes are common. The epithelium may be flat and atrophic or tall and secreting. With this multiplicity of possible changes it is not surprising that good and bad results are reported with almost any endocrine treatment and that spontaneous or placebo response may be as high as $70 \% .^{813}$

An exact knowledge of the aetiology of prostatic enlargement would provide a firmer basis for hormone treatment. The conjectures fashionable at present include alteration in the androgen/oestrogen balance ${ }^{14}$ or in the relative concentration of testosterone and its metabolites. ${ }^{15}$ Experimental evidence is conflicting. The condition does not fit neatly into the definition of hyperplasia or neoplasia, and the possibility of a virus as the initiating factor has not been fully excluded.

The reported trials of treatment with hormones do not show clinical improvement that is more than marginal, so that the general use of these drugs is unjustified at present, particularly when, with careful preoperative assessment by urologist and anaesthetist, the great majority of patients can undergo a transurethral resection.

\footnotetext{
1 Sunday Times, 29 August 1971, p. 5.

Rangno, R. E., McLeod, P. J., Ruedy, J., and Ogilvie, R. I., Clinical Pharmacology and Therapeutics, 1971, 12, 658.

British Medical fournal, 1970, 1, 583.

4 Gingell, J. C., et al., Proceedings of the Royal Society of Medicine (in press).

5 Aubrey, D. A., and Khosla, T., British fournal of Surgery, 1971, 58, 648.

- Burger, A. J. S., Medical Proceedings, 1968, 14, 116.

Theodorides, P., et al., Proceedings of the Royal Society of Medicine (in press).
} 
- Franks, L. M., in Advances in the Study of the Prostate. The Marie Curie Memorial Foundation Workshop Conference at the R.S.M. London, 1969, ed. D. C. Williams, M. H. Briggs and M. Staniford, p. 5. London, Heinemann, 1970 .

10 Randall, A., Surgical Pathology of Prostatic Obstructions. London, Bailliere, 1931 .

11 Mostofi, F. K., in Urology, ed. M. F. Campbell and J. H. Harrison, 3rd edn., p. 1065. London, W. B. Saunders, 1970.

12 Franks, L. M., Proceedings of the Royal Society of Medicine (in press). 13 Clarke, R., British fournal of Urology, 1937, 9, 254.

14 Roberts, H. J., fournal of the American Geriatrics Society, 1966, 14. 657.

15 Peeling, W. B., and Griffiths, K., Proceedings of the Royal Society of Medicine (in press).

\section{As You Were}

The recommendations in the first report from the new Review Body 1 - the thirteenth if Lord Kindersley's numbering had been continued-are much as expected (see Supplement, p. 64), though falling short of the B.M.A.'s claims (p. 67). By restoring the cuts made by the Government ${ }^{2}$ in the last award and adding nothing to the pay of those doctors who received the full $30 \%$, the objectives of the twelfth report ${ }^{3}$ have been respected. Of course, the cuts have meant many doctors irretrievably losing income between 1970 and 1971, but, given the short time in which Lord Halsbury was asked to report, this is an unexceptionable conclusion to his first exercise. The proposals, which cover the period April 1971 to March 1972, are now being considered by the B.M.A., the Government having accepted them.

At least four aspects of the report, which is concise and clearly written, merit close attention by doctors. Firstly, rapid inflation has now made the frequency of reviews a major issue and the Review Body sees them as occurring more often than Pilkington envisaged. ${ }^{4}$ Few doctors would quarrel with this, though the Government might ritually defend a two-year period of review. An annual exercise means more work for the negotiators as well as the Review Body, but infrequent reviews necessitate hazardous projections and may produce embarrassingly large increases.

Secondly, while not attempting to do more than restore the status quo in the pay of hospital doctors, the new Review Body has quickly scented the problem of relativities among hospital staff. The Government's interference in the last award necessitated some hasty juggling with the recommendations for the more junior consultants to avoid senior registrars overlapping their pay scale. The profession and the Health Departments disagreed about restoring previous relativities, and the whole issue will be reviewed next time.

Thirdly, referring back to Lord Kindersley's pricing of the family doctor contract in $1966,5^{5}$ the report tries to distinguish between the "net and the gross" elements in general practitioners' N.H.S. pay. Analysing the difficulties of doing this, it mentions the different calculations produced by the B.M.A. and the Health Departments for arriving at the twelfth report's intended target for general practitioners' average net pay in 1969-70. Despite showing the uncertainties in forecasting general practitioners' pay, the Review Body promises to state in future its intended average net income for them. A start is made in this report. Using an estimate of $£ 4,800$ as the average net income in 1969-70 and adding $8 \%$ the Review Body aims at $£ 5,185$ for 1971-2, with expenses calculated at an average of $£ 2,080$ per doctor.

"Our aim," states the Review Body in Chapter 3, "must be to make interim recommendations that are as fair as possible both to the profession and to the community." Hence clearly the present report is no more than a bridge between two major reviews. Thus sections of the profession disappointed by this review-and young consultants and doctors in training grades are bound to be so-will be specially interested in seeking clues in the final chapter entitled "Future Reviews" on the direction that successive reports might take. Short and to the point, this chapter shows a businesslike approach to examining the profession's pay. The quantity and quality of medical students, emigration, and the acquisition of "more systematic information than is available at present about the workload carried by doctors and dentists" are singled out for future study.

The Review Body will not limit itself to periodic evidence from the Government, doctors, and dentists. With the Office of Manpower Economics-which also serves two other independent review bodies-as secretariat, there will be frequent contacts between it, all professions, Government departments, and industries. Doctors may draw their own conclusions from these straws in the wind. Facts and figures are essential to any review, but the profession's negotiators can be relied upon in presenting the next round of evidence to make it clear that medicine cannot be seen just in terms of "cash flow," "cost-benefit," and "management efficiency." Fortunately, it is still a humanitarian and intensely personal activity.

\footnotetext{
${ }^{1}$ Report of the Review Body on Doctors' and Dentists' Remuneration 1971 Cmnd. 4825. London, H.M.S.O., 1971

2 British Medical fournal Supplement, 1970, 3, 87.

3 Review Body on Doctors' and Dentists' Remuneration, 12th Report, Cmnd. 4352. London, H.M.S.O., 1970.

' Royal Commission on Doctors' and Dentists' Remuneration, 1957-1960, Report, Cmnd. 939. London, H.M.S.O., 1960.

5 Review Body on Doctors' and Dentists' Remuneration, 7th Report, Cmnd. 2992. London, H.M.S.O., 1966.
}

\section{Mediastinal and Hilar Fibrosis}

Dense fibrous tissue laid down for no apparent reason is the outstanding feature of several disparate conditions. They include mediastinal fibrosis, hilar fibrosis, retroperitoneal fibrosis, Reidel's struma, sclerosing cholangitis, ligneous perityphlitis, and orbital pseudotumour. The coexistence of two or more of them has now been recorded sufficiently often for a common aetiology to be suspected at least in some of them.

The term multifocal fibrosclerosis has been suggested for the group. ${ }^{1}$ No satisfactory explanation for the fibrous reaction has yet been found. Searches for a genetic cause have yielded no more than the recording of two brothers with multifocal sclerosis. ${ }^{1}$ Immunological mechanisms have been sought in vain, though one patient with retroperitoneal fibrosis had hyperglobulinaemia and antinuclear factors. ${ }^{2}$ An infective granuloma, especially histoplasmosis, has been suggested in some cases of mediastinal fibrosis. Methysergide, used in the treatment of migraine, has been linked with the development of retroperitoneal fibrosis. There the matter rests.

Idiopathic fibrosis may affect any part of the mediastinum. The process appears to spread for a few months and then burn itself out, leaving a relatively acellular mass of limited extent which destroys tissue planes, infiltrates and then replaces the walls of major blood vessels, and compresses adjacent mediastinal structures. It occurs most frequently in the upper mediastinum, in patients over 40 years of age, and has 